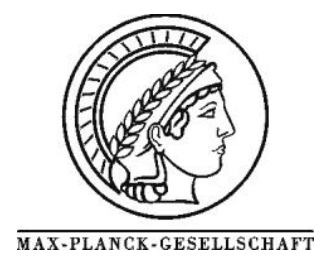

44. Jahrestreffen Deutscher Katalytiker, Weimar, 16.03.-18.03.2011

\title{
A new way of probing reaction networks: analyzing multidimensional parameter space
}

Raoul Naumann d'Alnoncourt, Yury V. Kolen'ko, Robert Schlögl, Annette Trunschke Department of Inorganic Chemistry, Fritz Haber Institute, Berlin, Germany

Technically relevant partial oxidation reactions can be very complex reaction networks. Establishing a microkinetic model for such networks is a nigh on unachievable goal. The one-step synthesis of acrylic acid from propane is such a reaction network. The most interesting catalysts for said reaction are Mo- $\mathrm{V}-\mathrm{Te}-\mathrm{Nb}$ mixed oxide phases, denoted as M1 and M2. ${ }^{1}$ Whether phase pure M1 or mixtures of M1 and M2 are the most efficient catalysts is still under debate. In literature, suitable reaction conditions are usually stated being in the temperature range of 280 $-420^{\circ} \mathrm{C}$ using a synthesis gas with high amounts of steam ( $\left.30-50 \%\right)$. Most often a stochiometric or nearly stochiometric mixture of propane and oxygen (1:2) is used with propane concentrations range from 2 to $8 \%{ }^{2}$

In an on-going study, a 10-fold parallel reactor set-up is used to screen conditions for said reaction in a wide range using a carefully chosen catalyst sample of phase-pure M1. The investigated catalyst is a phase-pure M1 sample prepared by consecutive steps of precipitation, spray drying, calcination, washing with hydrogen peroxide solution, and thermal activation in argon. Varied parameters include temperature, steam content, oxygen feed concentration, propane feed concentration, $\mathrm{CO}_{2}$ feed concentration, and contact time. Analysis of derived quantities like product yields or activation energies in multidimensional parameter space can give insight into the reaction network.

\section{Experimental}

Catalytic tests are carried out in a 10 -fold parallel reactor set-up designed by Integrated Lab Solutions (Berlin, Germany). Analysis of reactor effluent gas is done by on-line gas chromatography using an Agilent 7890 series GC equipped with a thermal conductivity detector and a flame ionization detector. The temperature is varied between 350 and $390^{\circ} \mathrm{C}$. A broad range of contact times $\left(0.06-1.44 \mathrm{~s} \mathrm{~g} \mathrm{ml}^{-1}\right)$ is applied. Propane feed concentration is varied between 1 and $3 \%$. Steam content is varied between 0 and $40 \%$. Oxygen feed concentration is varied between 4.5 and $12 \% . \mathrm{CO}_{2}$ feed concentration is varied between 0 and $40 \%$. 


\section{Results and Discussion}

As an example, Fig. 1 shows the yield of acrylic acid as a function of propane feed concentration and temperature for a given contact time of $0.72 \mathrm{~s} \mathrm{~g} \mathrm{ml}^{-1}$ (left side) and the influence of contact time and propane feed concentration at a temperature of $390^{\circ} \mathrm{C}$ (right side).
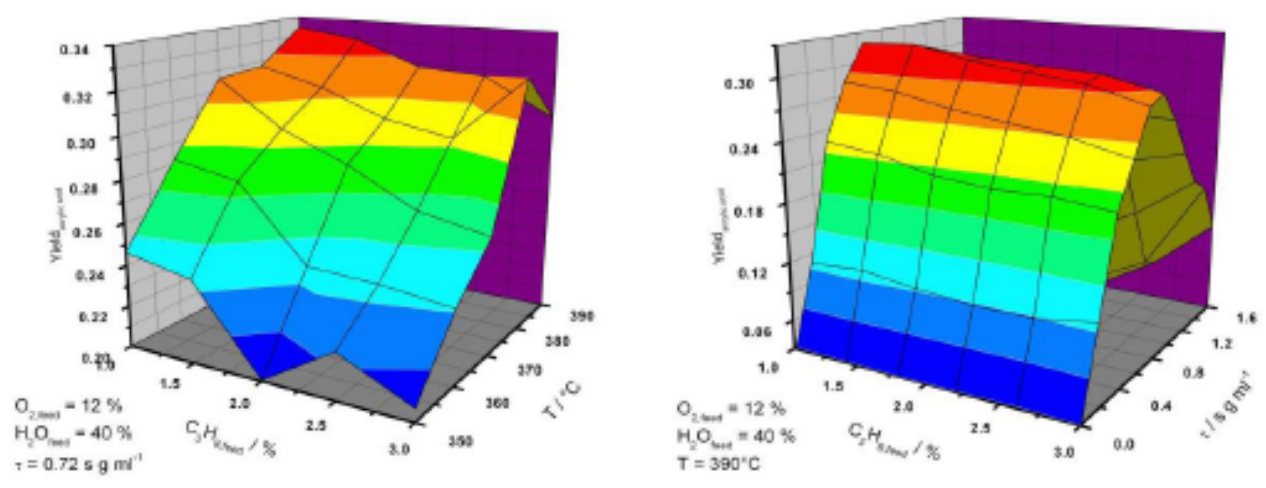

Fig. 1: $\mathrm{Y}_{\text {acryllc acla }}$ as a function of $\mathrm{C}_{3} \mathrm{H}_{8, \text { rəøa }}$ and $\mathrm{T}$ for $\tau=0.72 \mathrm{~s} \mathrm{~g} \mathrm{ml}^{-1}$ (left side) and as a function of $\mathrm{C}_{3} \mathrm{H}_{8, \text { reed }}$ and $\tau$ at $\mathrm{T}=390^{\circ} \mathrm{C}$ (right side)

Highest yields are found for a contact time of $0.72 \mathrm{~g} \mathrm{~s} \mathrm{ml}^{-1}$ and as a general trend at lower propane feed concentrations. This can be rationalized by the fact that selectivity to $\mathrm{CO}_{\mathrm{x}}$ increases with longer contact times and selectivity to acetic acid increases with higher propane feed concentration.

Analysis of the complete data set yields information about the reaction network. E. g., it can be concluded that acrylic acid is primary and secondary product and that at least two different active sites for acrylic acid synthesis exist on the catalyst surface, and that $\mathrm{CO}_{2}$, not $\mathrm{CO}$, is coproduct of the byproduct acetic acid.

\footnotetext{
${ }^{1}$ T. Ushikubo, H. Nakamura, Y. Koyasu, S. Wajiki, US Patent 5380933 (1995); Mitsubishi Kasei Corporation.

${ }^{2}$ A.Trunschke, "Propane Selective Oxidation to Acrylic Acid" in Nanostructured Catalysts: Selective Oxidation Reactions, Eds: C. Hess, R. Schlögl, submitted
} 